\title{
SPATIAL VARIABILITY OF EXPANSIVE SOIL PROPERTIES AT DIFFERENT SCALES WITHIN KIBAHA (TANZANIA)
}

CHARLES LUCIAN

(Received 17, February 2009; Revision Accepted 2, May 2009)

\section{ABSTRACT}

This paper applies statistical and geostatistical procedures to analyse the spatial distribution of several soil properties and use the contribution of ge ostatistics to plan optimal soil sampling and management schemes in Kibaha, Tanzania. Particle-size distribution, Atterberg limits and potential swell were analysed. Variogram models for clay content which is strongly correlated to the swell are constructed using the means of the soil properties. The variograms show that the distributions of all variables were not random but spatially-dependent as their estimated variogram values increased with increasing distance. The variograms predicted significantly slower horizontal variation and faster vertical variation of the clay content. The average range values vary between 20 and $30 \mathrm{~m}$ in horizontal separation and $1.0 \mathrm{~m}$ and $1.5 \mathrm{~m}$ in depths for particle-size distribution. It implies that if wishing to reduce the need for expensive and intensive sampling, then grid soil sampling will generally have to be performed at interval of less than half the range of spatial dependence of clay content depending on the attribute of interest.

KEYWORDS: Expansive soil properties; Kibaha, Tanzania; Atterberg Limits, Swell potential; Desriptive Statistics; Correlation.

\section{INTRODUCTION}

\section{General Introduction}

Spatial variability of various soil properties is inherent in nature due to soil forming factors, relief, parent material, climate, organisms, and time. Due to these usual processes, soil physical properties vary from one point to another across landscapes. Despite the deviation, spatial variation is not random but tends to follow a certain pattern in which the variability decreases with decrease in distance between points along the landscapes. Two samples close to each other are more likely to have small differences and those far apart big differences, while those much further apart are likely to be independent of each other (Lucian, $2008^{1}$ ). However, sampling at wider sample spacing may be sufficient for relatively homogeneous landscape while sampling at short intervals may be needed if the soils are quite heterogeneous. Unfortunately, very few studies take into account the spatial variability of soil parameters when soils are sampled.

Precision geotechnical sampling requires a method of gathering information about the spatial variability of soil that reduces the need for expensive and intensive sampling. Spatial analysis of the soil properties will quantify the distance of spatial correlation with a view to proposing suitable sampling locations, sampling numbers and frequency (Goovaerts, 1997, McBratney and Webster, 1983 and Warrick et al., 1986). This can be achieved through the use of what we term 'average' and 'proportional' variograms. Generally, the semivariogram is a measure of how the variance changes with distance. It is a univariate estimator, which describes the relationship between spatially correlated data.

Areas of focus in the literature review were primarily directed at gathering knowledge of semivariograms for multiple soil properties, allowing comparison of the magnitude of variability for interpreting and understanding spatial patterns (Myers, 1994, Nielsen, 1998 and Warrick et al. 1986). For soil properties that display proportionality between their mean squared and variance, the semivariogram can be predicted from a mean value. These average and proportional semivariograms are potentially beneficial to Geotechical Engineers in planning optimal soil sampling based on the range and nugget effect. To get reliable data in the area at a minimum cost, the average sampling interval of just less than half the variogram range should be adequate for future sampling, in case of small nugget effect (Flatman et al., 1987 and Kerry and Oliver, 2004). In case of large nugget effect, the sampling should be less than two-thirds of the range of correlation. Sampling less than this is wastage of investigation budget, while sampling further apart results into fewer points on the semi-variogram to determine a significant spatial relationship. In view of the above contribution and because of dearth of information on soils of Kibaha, Tanzania it was considered appropriate to conduct this research with the following objectives:

- $\quad$ To determine and evaluate soil properties at several locations where expansive soil is thought to exist.

- To characterize the spatial variability (variogram analysis) and spatial correlation of expansive soil properties.

- To estimate the best optimal soil sampling intensity related to soil variability.

To achieve the mentioned objectives above, a soil survey was conducted in a site with relatively expansive soils in Kibaha, Tanzania both at the subsurface and deep soil horizons. It was also necessary in this study to understand the spatial variability of soils and soil properties in both the horizontal and vertical orientations. Necessary soil information was obtained in the laboratory, including Atterberg limits, shrink-swell 
potential and free swell. After estimating variograms for horizontal and vertical directions using the necessary information, more approximate estimate of the sampling intensity was obtained.

\section{Study Area}

The experimental site is located in a swell prone area in Kibaha. Kibaha is positioned in semiarid areas of the Coastal Plain $\left(06^{\circ} 41^{\prime}-06^{\circ} 51^{\prime} \mathrm{S}\right.$ latitude and $38^{\circ} 50^{\prime}-$ $39^{\circ} 00^{\prime} \mathrm{E}$ longitude) of Tanzania, which is underlain largely by overconsolidated clays and cemented sandy clay to depths of several metres (Lucian, 2006). Nearly all soils of the area consist primarily of clay soils that have a high shrink-swell potential, associated with moderate amounts of sand. Generally, the soils vary slightly from one place to another and have, for the most part, irregular drainage and no definite water tables. The soils range from slowly permeable sandy loams; loams with unsatisfactory drainage; to clays with imperfect drainage. Generally, the soils have higher clay fractions along the valleys than on the ridge tops. There is also a trend towards decreasing clay contents at greater depths.

\section{Geology}

Soil characteristics in the coastal plain of Tanzania are strongly influenced by parent material, including sediments filling of fluviatile and alluvial deposits that comprise clay, calcareous sandstones, limestones, marine marls, shells, mud, organic materials and conglomerates of late Mesozoic and early Cenozoic (Mpanda, 1997, Lucian, 2006 and Lucian and Hintze, 2007). Therefore, the soils have significant amounts of expansive smectite (montmorillonite) minerals, resulting in shrink/swell potential. The higher degree of concentration of smectite is obtained from sediments of marine marls and shells (Lucian et al., 2006). It is interesting to note that the content of smectite varies with depth indicating that swell potential varies with depth as well (Lucian, 2006 and $2008^{2}$ ). Once again, this change calls for variability assessment study on the potential impact that smectite change in clay content can have on the swell potential.

\section{MATERIALS AND METHODS}

\section{Sampling}

In September 2007, soil samples were collected from different pits along a stretch of $60 \mathrm{~m}$ long each in east-west and north-south directions with the mean separation distance of $10 \mathrm{~m}$ between the pits, thereby providing 14 actual sampling locations or pits. To assess the variability in the vertical direction, samples were retrieved from six depth intervals to determine the vertical extent of soil properties that correlate with swell potential in each peat. The six depth intervals were $0.5 \mathrm{~m}, 1.0 \mathrm{~m}, 1.5 \mathrm{~m}, 2.0 \mathrm{~m}, 2.5$ and $3 \mathrm{~m}$ making a total of 84 counts of 'representative' sampling locations for the 14 test pits. The pits were excavated manually using pick-axes and trowels. The 6 soil horizons and horizon depths in each pit were determined using a knife and measuring tape. The samples were collected using hand tools such as knives, trowels and shovels and wrapped numerous times in aluminium foils and cling films and placed in plastic bags for transport to the laboratory for testing. For easy identification, the samples retrieved at each interval were marked with the numbers in the North - South direction and East - West direction as NS1, NS2 ....NS6 and EW1, EW2.....EW6 respectively. The samples from the junction of the two directions were used as the reference samples marked by R0.

\section{Laboratory Tests}

Laboratory analyses included particle-size distribution, Atterberg limits as indirect indicators of shrink-swell potential and free swell. Particle-size distribution reflects the relative amounts of different types of particles present, sorted according to size. Atterberg limits are measurements of contents of a soil at the points where it passes from one state of consistency to another, namely liquid limit, plastic limit and shrinkage limit. Liquid limit (LL) is the moisture content, in percent, at which a soil changes from a plastic state to a viscous liquid and begins to flow. Plastic limit $(\mathrm{PL})$ is the lowest moisture content, in percent, at which the soil can be rolled into threads 3 $\mathrm{mm}$ in diameter and maintain its shape without breaking into pieces. Similarly, the shrink age limit (SL) is the moisture of the oven-dried soil, in percent, at which further loss in moisture will not cause a decrease in its volume. The free swell percent is the property of soil that indicates the innate behaviour the soil has for swelling. The particle size distribution was accomplished in accordance with ASTM D422 while the Atterberg limits tests were conducted in accordance with ASTM D4318. The free swell tests on samples were tested using the methods of Holtz and Gibbs, 1956.

\section{DATA ANALYSIS}

Descriptive statistics of the total number of samples, mean, minimum and maximum values and coefficient of variability (standard deviation/mean) were evaluated for all soil properties. Furthermore, correlation was used to isolate soil property significantly related to swell index. The singled out soil property was used to assess the spatial variability of soil properties and recommend a suitable sampling scheme. The Spatial variability was assessed through semivariance analysis. The semivariogram function (Goovaerts, 1997 and Isaaks and Srivastava, 1989) was calculated as follows in equation 1 ; where $\gamma(h)$ is the semivariance, $(h)$ is the distance between sampling points (Lag), $N(h)$ is the number of sampling pairs of observation separated by lag distance $h$ (separation distance between sample positions), $Z\left(x_{i}\right)$ is a measured value of the property at spatial position $i, Z\left(x_{i}+h\right)$ is a measured value of the property at spatial position $i+h$.

The semi-variogram is expressed by variance curve as the functional diagram of the semi-variance $r(h)$ versus lag distance $h$ between the points. It consists of three basic parameters (nugget semivariance, range and sill or total variance) which describe the spatial structure of the spherical model as shown in Fig. 1:

where $C_{0}$ represents the nugget effect or variance at zero distance that represents the random spatial variability, $C$ is the structural component, $C_{0}+C$ is 
the sill which is the total or maximum semi-variance in the data at which the variogram levels off indicating the special variability of certain observational variables in the research field and $a$ is the range (Figure 1). The range of influence $a$ is the distance at which values of one variable become spatially independent of another.
The nugget variance $C_{0}$ is the point where the semivariogram intercepts the y-axis (i.e. at $h=0$ ). Practically, the semi-variogram passes through the origin ( $h=0, \gamma(h)=0$ ), since a pair of measurements taken at the same spatial location give the same result.

$\gamma(h)=\frac{1}{2 N(h)}\left\{\sum_{i=1}^{N(h)}\left[Z\left(x_{i}+h\right)-Z\left(x_{i}\right)\right]^{2}\right\} \ldots \ldots$
$\left.\gamma(h)=C_{0}+C\left[\frac{3}{2} \frac{h}{a}-\frac{1}{2}\left(\frac{h}{a}\right)^{3}\right]\right\} \begin{aligned} & \text { for } 0<h \leq a \\ & \text { for } h>a\end{aligned}$
$\gamma(h)=C_{0}+C$

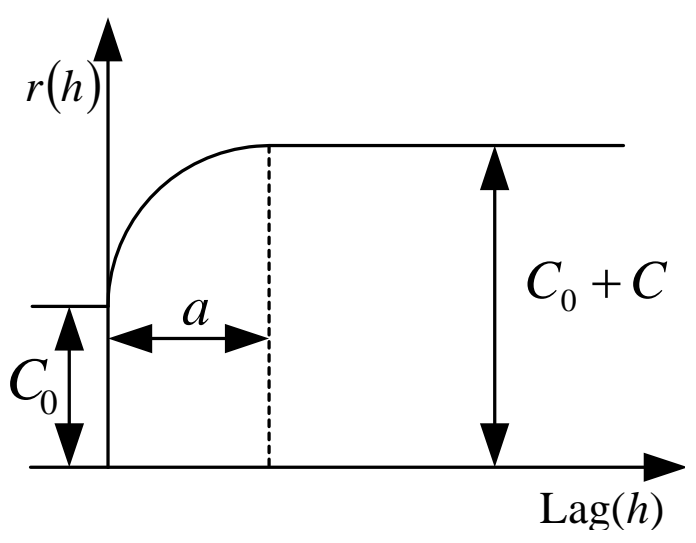

Figure 1: Semi-variogram of spherical fitted model (Dependence of semi-variance on the lag or separation between sample locations)

As $h$ increases, $r(h)$ rises to the maximum, approximately at a moderate value of $a$ which is the variance range (the upper limit below which the sampling data are correlated with each other). When $h \leq a$, it implies that samples have intrinsic relativity between one another, and the relativity decreases with the rise of $h$; and when $h>a$ it means that no relativity exists between samples. At small separation distances, the variance is small thus points that are near each other have a certain degree of spatial correlation but points that are widely separated are statically independent. After a certain level of separation, the variance becomes somewhat random and the model variogram flattens out suggesting that the variance among pairs of points are as similar for points separated by small distances as for those separated by larger points i.e. no spatial correlation in the data (Jones and Davis, 1996).

\section{RESULTS AND DISCUSSION}

The descriptive statistics for some expansive properties of soils in this study are shown in Table 1. The variability is highest for swell parameter and lowest for clay content based on the variance. Plastic limit and liquid limit exhibited a moderate degree of spatial variability. Generally, all properties showed low coefficient of variation (CV between 1 and $8 \%$ ). indicating that the dispersion of data points in each data series around the mean is small. This indicates that the soils are fairly homogeneous in texture and soil physical parameters are much more related across the landscape.

Normality of data was tested by examining skewness and kurtosis values. Tests for skewness showed swell potential, clay content and liquid limit to be positively skewed (long right tail of large values), while plastic limit and shrinkage limit to be negatively skewed (long left tail of small values). The kurtosis curve showed slightly negative platykurtic for most of the soil properties except for the clay which showed positive leptokurtosis. The correlation matrix shown in Table 2 describes the level of association between the swelling parameters and the soil properties. Clay content was found to be significantly high and positively correlated with the swelling parameters. The results justified the selection of the clay content components as the auxiliary variables for estimating the swelling parameters and construction of variograms. 
Table 1: Descriptive Statistics for some properties of expansive soils

\begin{tabular}{lcccrrrrr}
\hline & $\begin{array}{l}\text { Sample } \\
\end{array}$ & Size, N & Minimum & Maximum & Mean & Std. Dev. & C.V Skewness Kurtosis \\
\hline Swell & 84 & 100 & 150 & 120.48 & 11.50 & 9.5 & .34 & -.15 \\
Clay Content & 84 & 27.0 & 34.0 & 29.67 & 1.64 & 5.5 & .59 & .13 \\
Plastic Limit & 84 & 18.0 & 25.0 & 21.85 & 1.37 & 6.3 & -.12 & -.08 \\
Liquid Limit & 84 & 54.0 & 70.0 & 60.81 & 3.77 & 6.2 & .72 & -.41 \\
Shrinkage Limit & 84 & 10.0 & 15.0 & 12.55 & 1.06 & 8.3 & -.32 & -.15 \\
\hline
\end{tabular}

Table 2: Pearson correlations matrix of selected swelling soil parameters

\begin{tabular}{lrrrrr}
\hline & Free swell & Clay content & Plastic limit & Liquid limit & Shrinkage limit \\
\hline Free swell & 1 & & & & \\
Clay content & .78 & 1 & & & \\
Plastic limit & -.51 & -.72 & 1 & 1 & \\
Liquid limit & .68 & .72 & -.56 & -.58 & 1 \\
Shrinkage limit & -.60 & -.75 & .59 & -.58 \\
\hline
\end{tabular}

Table 3: The percentage clay content for horizontal separation along North - South direction

\begin{tabular}{lccccccc}
\hline Depth/Sample & R0 & NS1 & NS2 & NS3 & NS4 & NS5 & NS6 \\
\hline $0.5 \mathrm{~m}$ & 33 & 32 & 30 & 31 & 31 & 29 & 30 \\
$1.0 \mathrm{~m}$ & 34 & 33 & 29 & 28 & 30 & 29 & 30 \\
$1.5 \mathrm{~m}$ & 30 & 29 & 28 & 28 & 32 & 30 & 30 \\
$2.0 \mathrm{~m}$ & 32 & 30 & 28 & 27 & 28 & 28 & 29 \\
$2.5 \mathrm{~m}$ & 28 & 31 & 27 & 28 & 29 & 29 & 29 \\
$3.0 \mathrm{~m}$ & 31 & 30 & 28 & 27 & 30 & 29 & 29 \\
\hline
\end{tabular}

Table 4: Clay content spherical semivariogram model parameters for the investigated soil properties along North - South

\begin{tabular}{|c|c|c|c|c|c|c|c|c|c|}
\hline $\begin{array}{l}\text { Horizontal } \\
\text { Separation }\end{array}$ & $\gamma(10)$ & $\gamma(20)$ & $\gamma(30)$ & $\gamma(40)$ & $\gamma(50)$ & $\gamma(60)$ & Range & Sill & Nugget \\
\hline $\begin{array}{l}\text { Semi- } \\
\text { variogram }\end{array}$ & 1.5 & 2.8 & 2.9 & 2.4 & 3.4 & 3.3 & 26 & 3.1 & 0 \\
\hline $\begin{array}{l}\text { Vertical } \\
\text { Separation }\end{array}$ & $\gamma(0.5)$ & $\gamma(1.0)$ & $\gamma(1.5)$ & $\gamma(2.0)$ & $\gamma(2.5)$ & & & & \\
\hline $\begin{array}{l}\text { Semi- } \\
\text { variogram }\end{array}$ & 1.6 & 1.4 & 2.2 & 2.5 & 2.1 & & 0.9 & 2.0 & 0 \\
\hline
\end{tabular}

Table 5: The percentage clay content for horizontal separation along East - West direction

\begin{tabular}{lrrrrrrr}
\hline Depth/Sample & R0 & EW1 & EW2 & EW3 & EW4 & EW5 & EW6 \\
\hline $0.5 \mathrm{~m}$ & 33 & 32 & 30 & 29 & 30 & 31 & 31 \\
$1.0 \mathrm{~m}$ & 34 & 31 & 30 & 29 & 30 & 30 & 31 \\
$1.5 \mathrm{~m}$ & 30 & 30 & 29 & 27 & 29 & 28 & 30 \\
$2.0 \mathrm{~m}$ & 32 & 29 & 28 & 27 & 28 & 29 & 29 \\
$2.5 \mathrm{~m}$ & 28 & 30 & 27 & 28 & 29 & 30 & 30 \\
$3.0 \mathrm{~m}$ & 31 & 29 & 28 & 31 & 29 & 30 & 33 \\
\hline
\end{tabular}

Table 6: Clay content spherical semivariogram model parameters for the investigated soil properties along East - West direction

\begin{tabular}{|c|c|c|c|c|c|c|c|c|c|}
\hline $\begin{array}{l}\text { Horizontal } \\
\text { Separation }\end{array}$ & $\gamma(10)$ & $\gamma(20)$ & $\gamma(30)$ & $\gamma(40)$ & $\gamma(50)$ & $\gamma(60)$ & Range & Sill & Nugget \\
\hline $\begin{array}{l}\text { Semi- } \\
\text { variogram }\end{array}$ & 1.3 & 2.1 & 2.7 & 2.6 & 2.3 & 2.5 & 2.7 & 2.5 & 0 \\
\hline $\begin{array}{l}\text { Vertical } \\
\text { Separation }\end{array}$ & $\gamma(0.5)$ & $\gamma(1.0)$ & $\gamma(1.5)$ & $\gamma(2.0)$ & $\gamma(2.5)$ & & & & \\
\hline $\begin{array}{l}\text { Semi- } \\
\text { variogram }\end{array}$ & 1.3 & 1.8 & 2.6 & 2.4 & 1.9 & & 1.0 & 2.2 & 0 \\
\hline
\end{tabular}

The degree of spatial autocorrelation among the samples, for each variable and each direction (horizontal and vertical) was investigated by semi-variogram analysis (Figure 2 and Tables 3 to 6). The directional semivariogram analysis indicated that the horizontal direction had a larger average interval scale compared to the vertical direction. Both directions (east-west and north-south) and depths showed strong directional trends with no distinct differences among the structures of the calculated variograms in both directions. A large range value indicates that observed values of the soil property are influenced by other values of this property over great distances (Isaaks and Srivastava, 1989). For budget optimisation of sample the average spacing of 
future sampling should be of just less than half the range of spatial dependence, in case of small nugget effect (Flatman et al., 1987 and Kerry and Oliver, 2004). In case of large nugget effect, the sample spacing should be less than two-thirds of the range of correlation.
Sample spacing less than that is uneconomical, while spacing further apart results into fewer points on the semi-variogram to determine a significant spatial relationship.

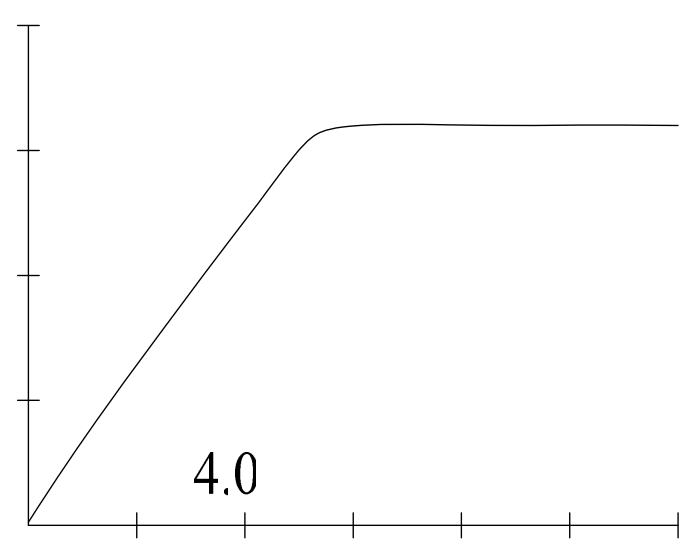

a) horizontal separation in North-South direction

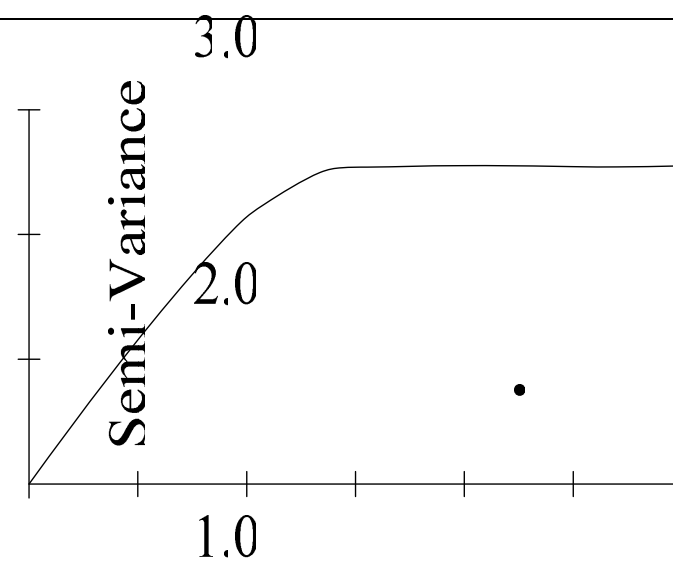

c) horizontal separation in East-West direction

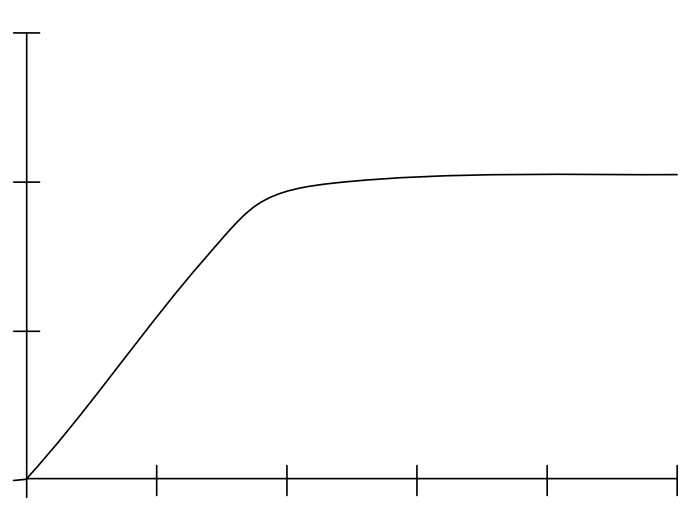

b) depth separation in North-South direction

Figure 2: Semi-variogram of percentage clay content

\section{CONCLUSIONS}

Spatial variability of expansive soil property was evaluated on representative site in Kißdha, Tanzani20 Generally, the clay content showed normal distribution with a relatively low coefficient of variability (CV), skewness and kurtosis. Furthermore, clay content was found to have high significant positive correlation with the swelling parameters. It is from such results that clay content has been found most appropriate to delineate swell potential that characterize Spatial variation in soil properties in Kibaha, Tanzania.

Clay content exhibited a consistent spatial variability pattern regarding the sampling length (horizontal direction) and depth (vertical direction) for both east-west and. horth south orientations. The variance range of clay contents were $20-30 \mathrm{~m}$ and 0.5 - $1.5 \mathrm{~m}$ in horizontal and vertical directions respectively. It implies that if wishing to reduce the need for expensive and intensive sampling, then grid soil sampling will gemerally have to be performed at 10 to 15 $\mathrm{m}$ and 0.5 to $1: 0$ mintervals in horizontal and vertical directions respectively for detection of spatial structure of clay content as well as swell potential. This is of practical importance in planning optimal soil sampling since the analysis of swell potential is more costly and time corlsuming thanthat of clay cobent.

\section{ACKNOWLEDGEMENT}

Separation Distance (m)

This research would not have been possible without the funding support from Sida/SAREC. I also wish to sincerely thank the laboratory staff at Dar es Salaam Institute of Technology (DIT) for diligently carrying out the necessary laboratory tests.

\section{REFERENCES}

ASTM D422-63., 2002. Standard test Methods for Particle-size Analysis of Soils. Annual Book of ASTM Standards, Section 4, Vol. 04.08, Soil and Rock; Building Stones. ASTM, Philadelphia

ASTM D4318-00., Standard test Methods for liquid Limit, Plasticity Limit, and Plasticity index of soils. Annual Book of ASTM Standards, Section 
4, Vol. 04.08, Soil and Rock; Building Stones. ASTM, Philadelphia.

Flatman, G. T., Englund, E. J. and Yfantis, A. A., 1987. Geostatistical approaches to the design of sampling regimes. In Keith, L. H. (Ed), Principal of Environmental Sampling. ASC Professional Reference Book. American Chemical Society, Washington.

Goovaerts, P., 1997. Geostatistics for natural resources evaluation. Oxford University Press, New York.

Holtz, W. G. and Gibbs, H. J., 1956. Engineering Properties of Expansive clays, Transactions, American Society of Civil Engineers, 121: 641677.

Isaaks, E. H. and Srivastava, R. M., 1989. An Introduction to Applied Geostatistics. Oxford University Press, New York.

Jones, N. L. and Davis, R. J., 1996. Three-Dimensional Characterization of Contaminant Plumes. Journal of Transportation Research Record, 1526: $177-182$

Kerry, R. and Oliver, M. A., 2004. Average variograms to guide soil sampling. International Journal of Applied Earth Observation and Geoinformation, 5, (4): 307-325

Lucian, C., 2006. Geotechnical Aspects of Building on Expansive Soils in Kibaha, Tanzania. Licentiate Thesis, Division of Soils and Rock Mechanics, Royal Institute of Technology (KTH), Stockholm, Sweden.

Lucian, C. and Hintze, S., 2007. Modelling Swelling Potential of Expansive Soils in Tanzania. The international Conference on Modelling and Simulation, Coimbatore, India, vol. 1: 623-628.

Lucian, C., Hintze, S. and Stille, H., 2006. Damage to Buildings on Expansive Soils in Kibaha, Tanzania. Journal of Building and Land Management, 13, (2): 39-47

Lucian, C., Hintze, S. and Stille, H., 2007. Geotechnical Characteristics of Swell-shrink Soils in Kibaha, Tanzania. Global Journal of Engineering Research, 6(1): 25 - 30.

Lucian, C., $2008^{1}$. Geotechnical Engineering Aspects of Buildings on Expansive Soils in Kibaha, Tanzania. PhD Thesis in Soil and Rock Mechanics, Royal Institute of Technology (KTH), Sweden

Lucian, C., $2008^{2}$. Geotechnical Engineering for Poverty Reduction: Practices for Constructing on Expansive Soils in Tanzania. RICS Construction and Building Research Conference, Dublin Institute of Technology, Ireland, http://www.rics.org/NR/rdonlyres/2A0E5591-B66D4AC6-BDB9-8D7284ADA54E/0/Lucian.pdf

McBratney, A. B. and Webster, R., 1983. How many observations are needed for regional estimation of soil properties? Journal of Soil Science, (135):177-183.

Mpanda, S., 1997. Geological development of the East Africa coastal basin of Tanzania. Stockholm contributions in Geology, Stockholm University, Department of Geology and Geochemistry, Stockholm, Sweden. 